
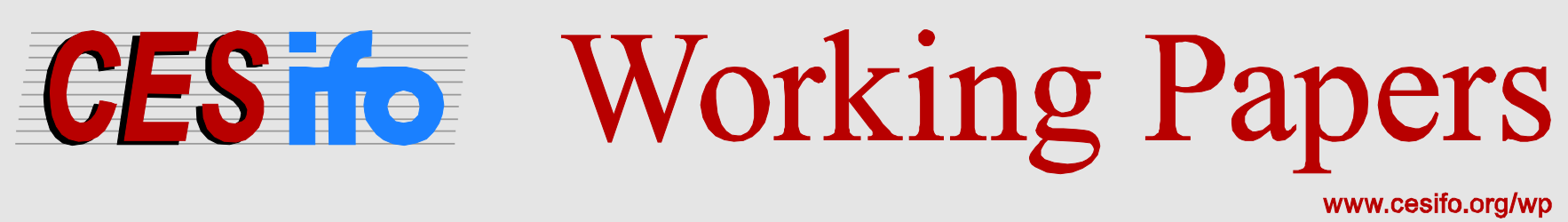

\title{
Agricultural Exports, Tariffs and Growth
}

\author{
Leonid V. Azarnert
}

CESIFO WORKING PAPER NO. 4583

CATEgORY 8: TRADE POLICY

JANUARY 2014

An electronic version of the paper may be downloaded

- from the SSRN website:

- from the RePEc website:

- from the CESifo website:

www.SSRN.com

Www.RePEc.org

www.CESifo-group.org/wp

\section{CESifo}




\title{
Agricultural Exports, Tariffs and Growth
}

\begin{abstract}
This article presents a Ricardian model of trade with learning-by-doing to study the effect of barriers to trade in products with low growth potential on the long-run economic growth. The model shows that, when elasticity of demand for the product with a lower learning potential is lower than unitary, a reduction in the tariff imposed on this product, may shift the demand toward the product with a higher learning potential, thus enhancing economic growth in the exporter economy. Therefore, the current trend of reduction in tariffs on agricultural exports not only generates a positive welfare effect in the short run, but may similarly be beneficial for developing economies in the long run, since it also increases their incentive to develop sectors with higher growth potential.
\end{abstract}

JEL-Code: F110, F150, F410, O410, Q170.

Keywords: trade barriers, agricultural export, learning-by-doing.

Leonid V. Azarnert

Department of Economics and

Business Administration

Ariel University

Israel - Ariel, 40700

Leonid.Azarnert@ariel.ac.il

I thank Editor-in-Chief, George S. Tavlas, and an anonymous referee for helpful comments and suggestions. 


\section{Introduction}

Large macro-econometric literature argues that free trade policies have had a positive effect on economic growth (e.g., Dollar 1992; Ben-David 1993; Edwards 1998; Sachs and Werner 1995; Harrison 1996; Krueger 1998; Frankel and Romer 1999; Greenaway, Morgan and Wright 2002: Dollar and Kraay 2004; Warcziarg and Welsh 2008, among many others). ${ }^{1}$ One of the channels through which trade can spur growth is its influence on sectoral composition: trade alters the relative prices and the resulting supply and demand of goods, and the sectoral composition of production determines the overall rate of growth if different goods have different rates of technological progress. The present paper focuses on compositional changes due to liberalization of trade in agricultural products that gradually occurs since the early 1990s. In particular, this work analyzes the effect of the current trend of reduction in agricultural tariffs on the incentive to develop sectors with higher growth potential in presently developing countries.

Agriculture, and to a lesser extent textiles and clothing, which represent other classical examples of the labor-intensive sectors with low growth potential, occupies an important place in trade negotiations. Since the early 1990s, serious efforts have been made to reduce barriers to trade in agricultural products in order to provide a better access to rich countries' markets for farm produce from poorer developing countries. Thus, in the early 1990s, under the Uruguay Round Agreement on Agriculture, developed countries reduced their tariffs on agricultural products by $37 \%$ on average, whilst the average reduction in tariffs on tropical products, which are of particular interest to developing countries, was $43 \%$ (see, for example, Henson and Loader (2001) for the details). ${ }^{2}$ Later on, at the 2000 Millennium Summit developed economies agreed to further increase market access for developing countries to help foster their economic growth. As a consequence, in the following years developed economies have further lowered their tariff barriers imposed on agriculture, textiles and clothing imported from developing countries (World Bank, 2010). However, despite the serious progress that has been achieved in this direction during the recent two decades, food products still face tariffs that are roughly 2.5

\footnotetext{
${ }^{1}$ See, however, Rodrik, Subrananian and Trebbi (2004) for a critical view.

${ }^{2}$ For further evidence on protection levels in agriculture before the Uruguay Round Agreement see, for example, Josling (1993).
} 
times higher than the average tariffs on machinery and transport equipment imported from these countries (World Bank, 2010). Moreover, nontariff barriers on agricultural products from developing countries sometimes are even higher than tariffs. ${ }^{3}$ As a consequence, numerous voices have repeatedly advocated further reductions in agricultural trade barriers.

This work presents a Ricardian model of trade that studies the effect of barriers to trade in the products with low growth potential on the long-run economic growth in exporting countries. The present analysis mostly develops on Matsuyama (1992) and Spilimbergo (2000). Thus, as in Matsuyama (1992), I assume that the elasticity of demand for agricultural good is smaller than unitary and that the engine of growth in the developing country is learning-by-doing in the manufactory sector, where the elasticity of demand is equal to one. The formal three-good and two-country structure of the model is borrowed from Spilimbergo (2000). Building on these two sources, the present model shows that if the product with a lower learning potential is characterized by a lower than unitary elasticity of demand, a reduction in tariffs imposed on such product can increase the demand for the product with a higher learning potential. The present analysis thus suggests that the current trend of liberalization of agricultural trade not only generates a positive short-run welfare effect for developing countries, but can also indirectly enhance their long-run economic growth.

The intuition behind this result is as follows. Suppose the world that consists of two entities: a developing home country and the rest of the world consolidated as a “foreign country”. Suppose there is one factor of production and three different goods, all produced with a constant return to scale technology. One good is a simple mature product such as agricultural products, or textiles, where developing countries generally have the biggest comparative advantages. Another good is a semi-sophisticated product, such as manufacture, which is still an advanced product for many developing countries. The third good represents all other products, where the rest of the world has its comparative

\footnotetext{
3 Thus, for example, while the World Bank's Tariff Trade Restrictiveness Index (TTRI) for 2007 for agricultural exports from low-income countries is slightly lower than 10\%, the corresponding Overall Trade Restrictiveness Index (OTRI) is slightly higher than 25\% (World Bank, 2010). For the role of sanitary and phytosanitary requirements in developed countries as barriers to agricultural exports from developing countries see, for instance, Henson and Loader (2001). A broader analysis of the consequences of
} 
advantage. The "foreign" good can, for example, be the high-tech products, where the advanced developed countries have the biggest comparative advantages. Similarly, it can also represent many other more traditional high-quality goods, such as exclusive cars, designers' clothes, or simply, foie gras, or a quality whisky, which are exported by the developed countries.

Suppose for simplicity that in the more advanced foreign economy all gains from learning have already been achieved and no further learning is possible. Similarly, in the less advanced home country there is no possibility for learning in the simple, as well as in the "foreign", sectors, but further learning is still possible in the semi-sophisticated sector. Suppose the comparative advantages are such that, when trade is allowed, the home country will produce and export the simple and semi-sophisticated goods, while the foreign country will specialize in its own "foreign" good. ${ }^{4}$

With technological progress modeled as learning-by-doing, it is straightforward that trade will increase the worldwide demand for the semi-sophisticated good, produced in the home country, thus stimulating technological progress in the home country and improving welfare in both countries. It is similarly clear that with unitary elasticity of demand any import tariff imposed in the foreign country on the simple good will proportionally decrease the demand for that good in the foreign country and reduce welfare, but it will have no effect on the demand for the semi-sophisticated good and then on the process of learning in the home country.

Proceeding now to the main insight of the present paper, let us suppose that the elasticity of demand for the simple (agricultural) good is lower than unitary. Now, with the non-constant shares of income allocated to different goods, a reduction in the import tariff imposed in the foreign country on the simple product will increase the foreign country's demand for that product less than proportionally, thereby causing a reallocation of resources toward the semi-sophisticated product. This will generate an additional stimulus for a further increase in the worldwide demand for the product with a potential

agricultural trade liberalization for developing countries can be found, for example, in Bureau, Jean, Matthews (2006).

${ }^{4}$ With such pattern of comparative advantage, allowing for learning in the "foreign" sector in the less advanced economy will not generate additional insights. 
for further learning. This in turn will intensify the learning process and technological progress in the semi-sophisticated sector in the home country. ${ }^{5}$

To fully concentrate on the pure effect of trade barriers per se, it is assumed in this paper that tariff revenues are fully appropriated by the absentee government and are not redistributed to the population in the foreign economy. As long as the revenues are collected on the simple good, adding redistribution will strengthen the paper's results, because the net effect will be to reduce the demand for the simple good and further increase the demand for the good with learning, relative to the benchmark case presented in the next section. ${ }^{6}$

\section{The Model}

In this section, I present and analyze the basic model with two countries: Home and Foreign. The population size of Home is normalized to one, while the population size of Foreign is $f$. I suppose that there is no international mobility of labor, while there is perfect mobility of labor across sectors. ${ }^{7}$ First, I introduce a demand function and specify the production side. Second, I consider the equilibrium in autarky and with international trade. Next, I proceed to the effect of the import tariff imposed in Foreign on the product without learning on technological progress in the exporter Home.

\subsection{Demand side}

In both countries the agents share the same endowments and the same preferences. In every period each agent is endowed with one unit of labor, which is supplied to the labor market at the price of 1 . The utility of an agent in country $j$ (= Home or Foreign) at time 0 is given by:

\footnotetext{
${ }^{5}$ Since an increase in the foreign demand for the semi-sophisticated product is the driving force behind this paper's main result, an alternative assumption of learning-by-exporting in this sector will yield a qualitatively similar result.

${ }^{6}$ For an analysis of the welfare implications of the distribution of tariff revenues see, for example, Galor (1994). Alogoskoufis (2014) shows that an economy that moves from autarky to openness will end up with a higher growth rate and a negative net external position if the world real interest rate is lower than its autarky equilibrium real interest rate.
} 


$$
W_{0}^{j}=\int_{0}^{\infty} U_{t}^{j} e^{-\rho t} d t,
$$

where $U_{t}^{j}$ is an instantaneous utility function in country $j$ at time $t$, and $\rho$ is the discount rate. The instantaneous utility function is of a Stone-Geary-type with a minimum consumption requirement, and it has three arguments (the goods $x, y$, and $z$ ): ${ }^{8}$

$$
U_{t}^{j}=\alpha \ln \left(x_{t}^{j}-X\right)+\beta \ln \left(y_{t}^{j}\right)+\gamma \ln \left(z_{t}^{j}\right),
$$

where $j$ specifies the country $(j=H, F), \quad X$ is a nonnegative constant and $\alpha, \beta, \gamma, \in(0,1), \alpha+\beta+\gamma=1$.

All goods are perishable, they cannot be accumulated, and saving is not possible, so that consumers maximize their instantaneous utility each period.

Standard maximization problem $\left(\max U_{t}^{j}\right.$ s. t. $\left.P_{x t}^{j} x_{t}^{j}+P_{y t}^{j} y_{t}^{j}+P_{z t}^{j} z_{t}^{j}=1\right)$, where $P_{i t}^{j}$ is the price for a good $i(=x, y, z)$ in country $j$ at time $t$ gives the demands for $x_{t}^{j}, y_{t}^{j}, z_{t}^{j}:$

$$
\begin{aligned}
& x_{t}^{j}=\frac{\alpha}{P_{x t}^{j}}\left(1+\frac{\beta+\gamma}{\alpha} P_{x t}^{j} X\right), \\
& y_{t}^{j}=\frac{\beta}{P_{y t}^{j}}\left(1-P_{x t}^{j} X\right), \\
& z_{t}^{j}=\frac{\gamma}{P_{z t}^{j}}\left(1-P_{x t}^{j} X\right) .
\end{aligned}
$$

An assumption that $P_{x t}^{j} X<1$ ensures that the demands for $x$ is always strictly positive. Given that population size of Home is normalized to 1, Eqs. (3) to (5) represent both individual and total demand in Home. Individual demand in Foreign is obtained by multiplying these equations by the relative wage in that country $\omega$, as specified below in Section 2.4. Similarly, the total demand in Foreign is obtained by multiplying the individual demand by $f$.

\footnotetext{
${ }^{7}$ In Azarnert (2004) I consider the effect of the opportunities abroad for the high-skilled taxpayers on taxation and then economic growth. Cf. also Azarnert (2012) where further references can be found.

${ }^{8}$ Although, following Spilimbergo (2000), I adopt a Stone-Geary-type utility function, the same result could be obtained using any utility function with elasticity of substitution smaller than one.
} 
Finally, we obtain the indirect utility function by plugging the demand for goods $x, y$, and $z$ (Eqs. (3) to (5)) into the instantaneous utility function (Eq. (2)):

$$
U_{t}^{j}=\ln \left(1-P_{x t}^{j} X\right)-\alpha \ln P_{x t}^{j}-\beta \ln P_{y t}^{j}-\gamma \ln P_{z t}^{j}+J,
$$

where $J \equiv \alpha \ln \alpha+\beta \ln \beta+\gamma \ln \gamma$.

\subsection{Supply side}

In both countries all the goods are produced using labor as the only input with a constant return to scale technology:

$$
x_{t}^{j}=\frac{1}{a_{x t}^{j}} L_{x t}^{j} ; y_{t}^{j}=\frac{1}{a_{y t}^{j}} L_{y t}^{j} ; z_{t}^{j}=\frac{1}{a_{z t}^{j}} L_{z t}^{j},
$$

where $L_{i t}^{j}$ is the number of workers employed in the production of good $i(=x, y, z)$ in country $j$ at time $t$ and $a_{i t}^{j}$ is a coefficient that is time-, country-, and good-specific.

In the terminology of the example given in the introduction, suppose that good $x$ is a simple mature product, such as agricultural products, or textiles, where developing countries generally have their comparative advantages. Good $y$ is a semi-sophisticated product, such as manufacture, which is an advanced product for many developing countries. Lastly, good $z$ represents all other products, where the rest of the world, consolidated as the foreign country, has a comparative advantage.

For simplicity, suppose that in the more advanced foreign country all gains from learning have already been achieved and no further learning is possible. Similarly, in the less advanced home country no learning is possible in the traditional sector $x$, as well as in the "foreign" sector $z$, but further learning is still possible in the semi-sophisticated sector $y$. Therefore, in Foreign, the unit labor requirement $\left(a_{i}^{j}\right)$ is constant for all three goods. In Home, the unit labor requirement is constant for goods $x$ and $z$, whereas for good $y$ it can change over time, because in sector $y$ technological progress is possible in this country as specified below. Suppose also that this technological progress is limited by a constant $a_{y}^{H} ; \lim _{t \rightarrow \infty} a_{y t}^{H}=a_{y}^{H}$. 
Technological progress, which is limited to the semi-sophisticated good $y$ in the home country, is country specific and operates through a learning-by-doing as, for example, in Krugman (1987), Lucas (1988), Matsuyama (1992), and Spilimbergo (2000). The percentage reduction in the production cost is proportional to the number of workers employed in the production and to a constant $\xi$ :

$$
\frac{\dot{a}_{y t}^{H}}{a_{y t}^{H}}=-\xi L_{y t}^{H},
$$

where $L_{y t}^{H}$ represents the number of workers who are employed in the production of the good $y$ in the home country at time $t$.

The two countries have different technologies. The comparative advantages are assumed to be as follows:

$$
\frac{a_{z}^{H}}{a_{z}^{F}}>\frac{a_{y t}^{H}}{a_{y}^{F}}>\frac{a_{x}^{H}}{a_{x}^{F}}, \quad a_{y t}^{H} \geq a_{y}^{H} .
$$

Suppose that if, when trade is allowed, an import tariff at the rate $\tau$ is imposed in the foreign country on good $x$ imported from the home country, this does not affect the comparative advantages, so that: ${ }^{9}$

$$
\frac{a_{z}^{H}}{a_{z}^{F}}>\frac{a_{y t}^{H}}{a_{y}^{F}}>\frac{a_{x}^{H}(1+\tau)}{a_{x}^{F}} .
$$

Except for the tariff, I assume a competitive environment in both countries, so that in a closed economy $P_{x t}^{j}=a_{x}^{j} ; P_{z t}^{j}=a_{z}^{j} ; P_{y t}^{F}=a_{y}^{F} ; P_{y t}^{H}=a_{y t}^{H}$. To concentrate on the pure effect of the trade barriers per se, suppose that tariff revenues are fully appropriated by the absentee government and are not redistributed to the population in Foreign.

\subsection{Equilibrium in autarky}

\footnotetext{
${ }^{9}$ Formally, this condition implies that technological progress in sector $y$ in the home country sets the upper bound for the tariffs imposed on the good produced in sector $x$. Recent models with an endogenous emergence of comparative advantages can be found, for instance, in Fajgelbaum, Grossman and Helpman (2011) and Jaimovich and Merella (2011).
} 
In this section, I determine the relative prices faced by consumers, the relative demands, and the dynamics of the autarkic economy. I present the home and foreign economies separately.

Note that in Home, the demand for $y$ changes over time, because it depends on $a_{y t}^{H}$, which decreases over time owing to technological progress. The time path of $a_{y t}^{H}$ depends, through the formula for the learning-by-doing (Eq. (8)), on the number of workers employed in sector $y\left(L_{y t}^{H}\right)$ and on the demand for $y$ (Eq. (4)). Using equations (8) and (4), and noting that $P_{x t}^{H}=a_{x}^{H}$ and $P_{z t}^{H}=a_{z}^{H}$, we can obtain the rate of growth of $a_{y t}^{H}:$

$$
\frac{\dot{a}_{y t}^{H}}{a_{y t}^{H}}=-\xi L_{y t}^{H}=-\xi \beta\left(1-a_{x}^{H} X\right),
$$

or

$$
a_{y t}^{H}=a_{y 0}^{H} e^{-\xi D^{H, a} t} \text {, where } D^{H, a} \equiv \beta\left(1-a_{x}^{H} X\right) .
$$

Plugging $a_{x}^{H}, a_{y t}^{H}$ and $a_{z}^{H}$ for $P_{x t}^{H}, P_{z t}^{H}$ and $P_{y t}^{H}$ into Eq. (6), we can obtain the utility in Home in autarky at time $t$ :

$$
U_{t}^{H}=\ln \left(1-a_{x}^{H} X\right)-\alpha \ln a_{x}^{H}-\beta \ln a_{y 0}^{H}-\gamma \ln a_{z}^{H}+\xi \beta D^{H, a} t+J
$$

Therefore, the welfare in Home in autarky at time 0 is:

$$
W_{0}^{H}=\int_{0}^{\infty} U_{t}^{H} e^{-\rho t} d t=\int_{0}^{\infty} S^{H, a} e^{-\rho t} d t+\xi \int_{0}^{\infty} D^{H, a} t e^{-\rho t} d t=\frac{S^{H, a}}{\rho}+\frac{\xi D^{H, a}}{\rho^{2}},
$$

where $S^{H, a} \equiv \ln \left(1-a_{x}^{H} X\right)-\alpha \ln a_{x}^{H}-\beta \ln a_{y 0}^{H}-\gamma \ln a_{z}^{H}+J$.

As in Spilimbergo (2000), the utility in Home is thus decomposed into two components: a static component $\left(S^{H, a} / \rho\right)$, which depends on the present state of the technology $\left(a_{x}^{H}, a_{y 0}^{H}, a_{z}^{H}\right)$, and a dynamic component ( $\left.\xi D^{H, a} / \rho^{2}\right)$, which depends on the accumulation rate of technological progress and on the amount of labor employed in the production of $y$. 
In contrast to Home, in Foreign in autarky the demand for all three goods are constant over time. Therefore, plugging $a_{x}^{F}, a_{y}^{F}$ and $a_{z}^{F}$ for $P_{x t}^{F}, P_{z t}^{F}$ and $P_{y t}^{F}$ into Eq. (6), the utility in Foreign in autarky at time $t$ :

$$
U_{t}^{F}=\ln \left(1-a_{x}^{F} X\right)-\alpha \ln a_{x}^{F}-\beta \ln a_{y}^{F}-\gamma \ln a_{z}^{F}+J
$$

and the welfare in Foreign in autarky at time 0 is:

$$
W_{0}^{F}=\int_{0}^{\infty} U_{t}^{F} e^{-\rho t} d t=\int_{0}^{\infty} S^{F, a} e^{-\rho t} d t=\frac{S^{F, a}}{\rho},
$$

where $S^{F, a} \equiv \ln \left(1-a_{x}^{F} X\right)-\alpha \ln a_{x}^{F}-\beta \ln a_{y}^{F}-\gamma \ln a_{z}^{F}+J$.

Since, by assumption, further learning is not possible in the developed foreign economy, in contrast to Home, there is no dynamic component in the utility in Foreign.

\subsection{International trade}

In this section international trade is allowed. The equilibrium with trade between Home and Foreign is supposed to satisfy two conditions: first, production must be split according to comparative advantages; second, trade must be balanced. These two conditions determine the range of goods produced in Home and in Foreign and the relative wage between Home and Foreign. Using the wage in Home as numeraire, we define $\omega$ as the wage in the foreign country in terms of the wage in the home country.

\subsubsection{Comparative advantages}

The first condition states that the location of the production of the goods is split according to comparative advantages. Home has a comparative advantage in the production of the simple good $x$ and the semi-sophisticated good $y$, while Foreign has a comparative advantage in the production of the good $z$ (Eq. (9a)). Further, I suppose that, when trade is allowed, Home will produce and export the goods $x$ and $y$, while Foreign will produce and export the good $z$.

\subsubsection{Balanced trade}


The second condition states that trade must be balanced. To find the level of $\omega$, which solves this condition, we have to determine the relative prices in both countries. Given the specialization pattern and the tariff at the rate $\tau$ imposed in Foreign on the simple good $x$ imported from Home, the relative prices are:

$$
\text { in Home }=\left\{\begin{array}{l}
P_{x t}^{H}=a_{x}^{H} \\
P_{y t}^{H}=a_{y t}^{H} \\
P_{z t}^{H}=a_{z}^{F} \omega
\end{array} \quad \text { and in Foreign }=\left\{\begin{array}{l}
P_{x t}^{F}=a_{x}^{H}(1+\tau) / \omega \\
P_{y t}^{F}=a_{y t}^{H} / \omega \\
P_{z t}^{F}=a_{z}^{F}
\end{array}\right.\right.
$$

The balanced trade condition requires that the value of the import of the home country should equal the value of the import of the foreign country:

$$
z_{t}^{H} P_{z t}^{H}=\left(x_{t}^{F} P_{x t}^{F}+y_{t}^{F} P_{y t}^{F}\right) f \omega .
$$

Therefore,

$$
z_{t}^{H} P_{z t}^{H}=\left(1-z_{t}^{F} P_{z t}^{F}\right) f \omega .
$$

Substituting the demand for $x$ in Home and Foreign in Eq. (18) yields the equilibrium level of $\omega:{ }^{10}$

$$
\omega=\frac{\gamma\left(1-a_{x}^{H} X(1+(1+\tau) f)\right)}{(1-\gamma) f} .
$$

Note that $\omega$ depends only on parameters that are constant over time and the tariff $(\tau)$, which is given exogenously.

\subsection{Growth with free trade and with tariff}

Recall that, as follows from comparative advantages, once trade starts, Foreign stops producing $y$. Hence, with trade, the total amount of $y$ worldwide is supplied by Home, where, in contrast to Foreign, further learning in sector $y$ is still possible.

With $\omega$ as given in Eq. (19), the prices of the imported goods $x$ and $y$ in Foreign are:

\footnotetext{
10 The steps to compute $\omega$ are: $\gamma\left(1-P_{x t}^{H} X\right)=\left[1-\gamma\left(1-P_{x t}^{F} X\right)\right] f \omega \Rightarrow \gamma\left(1-a_{x}^{H} X\right)=\left[1-\gamma\left(1-\frac{a_{x}^{H}(1+\tau)}{\omega} X\right)\right] f \omega$.
}

Solving this equality for $\omega$ gives equation (19). 


$$
P_{x}^{F}=\frac{(1-\gamma) f}{\gamma\left(\left(\left(1 / a_{x}^{H}\right)-X\right)(1+\tau)^{-1}+f X\right)} .
$$

and

$$
P_{y t}^{F}=\frac{(1-\gamma) a_{y t}^{H} f}{\gamma\left(1-a_{x}^{H} X(1+(1+\tau) f)\right)} .
$$

Similarly, the price of the imported good $z$ in Home is:

$$
P_{z}^{H}=\frac{\gamma\left(1-a_{x}^{H} X(1+(1+\tau) f)\right)}{(1-\gamma)\left(f / a_{z}^{F}\right)} .
$$

With any non-negative tariff imposed on the simple good $x$ imported from Home ( $\tau>0)$, the price of this good in Foreign $\left(P_{x}^{F}\right)$ is higher than with free trade $(\tau=0)$. At the same time, due to the indirect effect of the tariff imposed on $x$ through its impact on the relative wage $\omega$, the price of the semi-sophisticated good $y$ in Foreign $\left(P_{y t}^{F}\right)$ is also higher than with free trade. Clearly, the change in the prices, relative to the free trade, is likely to reduce the demand for the imported simple good $x$, as well as for the imported semi-sophisticated good $y$ in Foreign. Note also that via its effect on the relative wage $\omega$, the tariff also affects the price of the imported good $z$ in Home $\left(P_{z}^{H}\right)$, thus additionally reducing the demand for the domestically produced products in Home. This allows us to hypothesize that the change in the worldwide demand pattern is likely to reduce the total worldwide demand for the semi-sophisticated product $y$, thus discouraging the learning-by-doing process in sector $y$ in Home.

To verify this hypothesis, compute first the total worldwide demand for $y_{t}:{ }^{11}$

$$
y_{t}^{H, t r}+y_{t}^{F, t r}=\frac{1}{a_{y t}^{H}} D^{t r},
$$

where $D^{t r} \equiv \beta\left(\left(1-a_{x}^{H} X(1+(1+\tau) f)\right) /(1-\gamma)\right)$.

\footnotetext{
${ }^{11}$ The total demand for $y_{t}$ is the sum of the demands in Home and in Foreign. The total demand for $y_{t}$ is:

$$
\begin{aligned}
& y_{t}^{H, t r}+y_{t}^{F, t r}=\frac{\beta}{P_{y t}^{H}}\left(1-P_{x t}^{H} X\right)+\frac{\beta}{P_{y t}^{F}}\left(1-P_{x t}^{F} X\right) f \\
& =\frac{\beta}{a_{y t}^{H}}\left(1-a_{x}^{H} X\right)+\frac{\beta \omega}{a_{y t}^{F}}\left(1-\frac{a_{x}^{H}(1+\tau)}{\omega} X\right) f=\frac{\beta}{a_{y t}^{H}}\left(1-a_{x}^{H} X(1+(1+\tau) f)+\omega f\right) .
\end{aligned}
$$
}


Note however that, when $X=0$, the prices of the goods $y$ in Foreign $\left(P_{y t}^{F}\right)$ and $z$ in Home $\left(P_{z}^{H}\right)$, as shown in Eqs. (21) and (22), respectively, are not affected by the tariff imposed on $x$ and therefore the worldwide demand for $y$ (Eq. 23) is also not affected by $\tau$.

Given the production function, as specified in Eq. (7), the total amount of labor in sector $y$ is $L_{y t}^{H}=D^{t r}$. From Eq. (23), it is clear that with any $\tau>0$ the total amount of labor employed in sector $y$ in Home is lower than with $\tau=0$. Namely, any tariff $\tau \geq 0$ is associated with a reduction in the amount of labor producing the semi-sophisticated product y by:

$$
{ }_{\Delta} L_{y t}^{t r}(\tau \geq 0) \equiv L_{y t}^{t r}(\tau>0)-L_{y t}^{t r}(\tau=0)=\tau \frac{\beta a_{x}^{H} X f}{1-\gamma} .
$$

The labor force in sector $y$ determines the temporal path of the coefficient $a_{y t}^{H}$ according to the learning-by-doing process $\left(\frac{\dot{a}_{y t}^{H}}{a_{y t}^{H}}=-\xi L_{y t}^{H}=-\xi D^{t r}\right): a_{y t}^{H}=a_{y 0}^{H} e^{-\xi D_{0}^{t r} t}$. Therefore, any tariff imposed on the simple good $x$ leads to the one-period percentage increase in the production cost of the semi-sophisticated good $y$ by: $\tau \xi \frac{\beta a_{x}^{H} X f}{1-\gamma}$. This implies that any tariff on $x$ changes the whole temporal path of the coefficient $a_{y t}^{H}$ and thus any $\tau \geq 0$ generates the following reduction in the learning-by-doing process in sector $y$ :

$$
{ }_{\Delta} a_{y t}^{H} \equiv a_{y t}^{H}(\tau \geq 0)-a_{y t}^{H}(\tau=0)=a_{y 0}^{H}\left[e^{-\xi D_{\tau \geq 0}^{t r} t}-e^{-\xi D_{\tau=0}^{t r} t}\right] .
$$

This allows us to establish the following result.

Proposition 1: A reduction in the import tariff imposed in Foreign on the simple good $x$ with elasticity of demand lower than unitary produced in Home shifts the worldwide demand pattern toward the semi-sophisticated good $y$, thus encouraging technological progress in sector $y$ in the Home.

Plugging in the equation for $\omega$ (19) and simplifying gives equation (23). 


\section{Conclusion}

This work presents a Ricardian model of trade with technological progress, modeled as learning-by-doing, to study the effect of barriers to trade in the products with low growth potential, such as agriculture, on the long-run economic growth. The model shows that, when elasticity of demand for the product with a lower learning potential is lower than unitary, a reduction in the tariff imposed on this product, may shift the demand toward the product with a higher learning potential, thus enhancing economic growth in the exporter economy. Therefore, the present analysis suggests that the current trend of liberalization of agricultural trade not only generates a positive effect on the welfare in the short run, but may also spur the long run growth prospects of the poorer developing countries.

\section{References}

Alogoskoufis, G. (2014) Endogenous growth and external balance in a small open economy. Open Economies Review (Forthcoming).

Azarnert, L.V. (2004). Redistribution, fertility, and growth: the effect of the opportunities abroad. European Economic Review 48, 785-795.

Azarnert, L.V. (2012). Guest-worker migration, human capital and fertility. Review of Development Economics 16, 318-330.

Ben-David, D. (1993). Equalizing exchange: trade liberalization and income convergence. Quarterly Journal of Economics 108, 653-679.

Bureau, J.-C., Jean, S., Matthews, A. (2006). The consequences of agricultural trade liberalization for developing countries: distinguishing between genuine benefits and false hopes. World Trade Review 5, 225-249.

Dollar, D. (1992). Outward-oriented developing economies really do grow more rapidly: evidence from 95 LDCs, 1976-85. Economic Development and Cultural Change 40, 523-544.

Dollar, D., Kraay, A. (2004). Trade, growth, and poverty. Economic Journal 114, F22F49. 
Edwards, S. (1998). Openness, productivity and growth: what do we really know? Economic Journal 108, 383-398.

Fajgelbaum, P.D., Grossman, G.M., Helpman, E. (2011). Income distribution, product quality, and international trade. Journal of Political Economy 119, 721-765.

Galor, O. (1994). Tariffs, income distribution and welfare in small overlappinggeneration economy. International Economic Review 35, 173-192.

Greenaway, D., Morgan, W., Wright, P. (2002). Trade liberalization and growth in developing countries. Journal of Development Economics 67, 229-244.

Harrison, A. (1996). Openness and growth: a time-series, cross-country analysis for developing countries. Journal of Development Economics 48, 419-447.

Henson, S., Loader, R. (2001). Barriers to agricultural exports from developing countries: the role of sanitary and phytosanitary requirement. World Development 29, 85-102.

Jaimovich, E., Merella, V., (2011). Love for quality, comparative advantages, and trade. Carlo Alberto Notebooks, no. 216.

Josling, T. (1993). Protectionism in agriculture: Slow progress toward freer trade in agricultural products. Open Economies Review 4, 211-228.

Krueger, A.O. (1998). Why trade liberalization is good for growth? Economic Journal 108, 1513-1522.

Krugman, P. (1987). The narrow moving band, the Dutch Disease, and the competitive consequences of Mrs. Thatcher: Notes on trade in the presence of dynamic scale economies. Journal of Development Economics 27, 41-55.

Lucas, R. (1988). On the mechanics of economic development. Journal of Monetary Economics 22, 3-22.

Matsuyama, K. (1992). Agricultural productivity, comparative advantage, and economic growth. Journal of Economic Theory 58, 317-334.

Spilimbergo, A. (2000). Growth and trade: the North can lose. Journal of Economic Growth 5, 131-146.

Wacziarg, R, Welsh, K.H. (2008). Trade liberalization and growth: new evidence. World Bank Economic Review 22, 187-231.

World Bank (2010). World Development Indicators, Washington, DC: World Bank. 